\title{
Stress-echocardiography in idiopathic dilated cardiomyopathy: instructions for use
}

\author{
Aleksandar N Neskovic*1,2 and Petar Otasevic ${ }^{1,2}$
}

Address: ${ }^{1}$ Cardiovascular Research Center, Dedinje Cardiovascular Institute, Belgrade, Serbia and Montenegro and ${ }^{2}$ Belgrade University Medical School, Belgrade, Serbia and Montenegro

Email: Aleksandar N Neskovic* - neskovic@hotmail.com; Petar Otasevic - otasp@eunet.yu

* Corresponding author

Published: 10 February 2005

Cardiovascular Ultrasound 2005, 3:3 doi:10.1 |86/1476-7|20-3-3
Received: 08 January 2005

Accepted: 10 February 2005

This article is available from: http://www.cardiovascularultrasound.com/content/3/l/3

(c) 2005 Neskovic and Otasevic; licensee BioMed Central Ltd.

This is an Open Access article distributed under the terms of the Creative Commons Attribution License (http://creativecommons.org/licenses/by/2.0), which permits unrestricted use, distribution, and reproduction in any medium, provided the original work is properly cited.

\begin{abstract}
A number of studies have suggested that stress-echocardiography may be used for prognostic stratification in patients with idiopathic dilated cardiomyopathy. There is no consensus on which protocol or which measurements of left ventricular contractile reserve to use. The most frequently used protocol is low-dose dobutamine stress-echocardiography, and most commonly used measures of left ventricular systolic performance are ejection fraction, wall motion score index and cardiac power output.

Stress-echocardiography has been shown to predict improvement in cardiac function in patients with recently diagnosed dilated cardiomyopathy, as well as to predict which patients will benefit from the treatment with beta-blockers. Most importantly, stress-echocardiography can identify patients with worse prognosis in terms of cardiac death and need for transplantation. Additionally, contractile reserve is closely correlated with maximal oxygen consumption and can even be used for further stratification in patients with maximal oxygen consumption between 10 and $14 \mathrm{ml} / \mathrm{kg} /$ $\min$.

Future studies are needed for head-to-head comparison of various protocols in an attempt to make standardization in the assessment of patients with dilated cardiomyopathy.
\end{abstract}

Epidemiologic data from United States indicate that idiopathic dilated cardiomyopathy (DCM) is diagnosed in approximately $36 / 100.000$ persons each year, and that it is responsible for more than 10.000 deaths per year [1]. Faced with the fact that the number of patients with DCM is constantly increasing [2], accurate assessment of patient's current status and prognosis is of the utmost importance for the implementation of optimal therapeu- tic algorithm as well as for the optimal utilization of resources.

\section{Why stress-echocardiography?}

There is a widespread belief that maximal oxygen consumption, assessed by cardiopulmonary testing, is one of most, if not the most important prognostic variables in DCM patients [3]. Maximal oxygen consumption is traditionally used for selection of patients for cardiac 
transplantation, with a values less than $12-14 \mathrm{ml} / \mathrm{kg} / \mathrm{min}$ indicating poor prognosis and need for transplantation $[4,5]$. This approach is based upon assumption that maximal oxygen consumption during cardiopulmonary testing is determined exclusively by cardiovascular factors.

However, it appears that other factors have considerable influence on maximal oxygen consumption, since it has been shown that regular physical exercise can augment oxygen consumption with little or no impact on other parameters of cardiovascular function [6]. Additionally, a normal blood flow through lower limbs was found in patients who stopped cardiopulmonary testing because of fatigue, indicating skeletal muscle dysfunction rather than pump failure [7] Patient's age and sex, as well as muscle mass are also shown to have strong influence on performance during cardiopulmonary testing [8]. Furthermore, it appears that patients with various degrees of cardiovascular impairment may yield similar maximal oxygen consumption, suggesting that there is a role for other procedures in risk stratification of patients with DCM [9].

A number of studies have shown that assessment of ventricular contractile reserve by means of stress-echocardiography may refine prognosis in patients with left ventricular systolic dysfunction [10-12]. Nevertheless, stress-echocardiography is widely underused in routine work-up in patients with heart failure, probably because of the unfamiliarity with the technique in this clinical setting.

The aim of this review is to put stress-echocardiography in DCM patients in clinical context, to give practical tips how to perform it and what to measure, as well as to try to define its role in everyday clinical practice.

\section{How to perform stress-echocardiography in DCM?}

Unlike protocols for stress-echocardiography for coronary artery disease, there is no consensus about the protocol to be used in patients with left ventricular systolic dysfunction.

The majority of authors have used either low- or highdose dobutamine echocardiography $[13,14]$. Low-dose is usually defined as $10 \mathrm{mcg} / \mathrm{kg} / \mathrm{min}$ of dobutamine [13], although some authors also consider $20 \mathrm{mcg} / \mathrm{kg} / \mathrm{min}$ as a low-dose infusion [15] High-dose is uniformly defined as $40 \mathrm{mcg} / \mathrm{kg} / \mathrm{min}$ [10]. There is no consensus either on duration of each stage of dobutamine infusion, since some authors use 3-minute stage [16] while the others use 5-minute stage [10] Most authors withdraw beta-blockers prior to stress-echocardiography, but some do not [15] Atropine is generally not used to achieve submaximal heart rate.
Exercise testing has been used for the assessment of left ventricular contractile reserve but in conjuction with radionuclide angiography [17] and hemodynamic measurements [18]. The usual protocol is performed on supine bicycle in incremental stages of $25 \mathrm{~W}$ lasting three minutes each. There are no data about the value of exercise stress echocardiography in DCM patients. It can be assumed that exercise stress-echocardiography would have the same limitations as cardiopulmonary testing.

Dipyridamole stress-echocardiography has been proposed for stratification of patients with DCM. Standard high-dose dipyridamole protocol $(0.84 \mathrm{mg}$ over $10 \mathrm{~min}$ utes) has been used for the assessment of contractile reserve [19].

\section{What to measure?}

All studies on stress-echocardiography in DCM measured contractile reserve of the left ventricle. Contractile reserve is defined as the difference between values of an index of left ventricular contractility during peak stress and its baseline values. There is no consensus on what index to use.

\section{Ejection fraction}

This is the most frequently used index of left ventricular performance. However, it may not accurately reflect left ventricular contractility since it is heavily dependent on loading conditions [20] which is particularly important in patients with heart failure for the following reasons. First of all, mitral regurgitation is frequent in these patients, and can lead to overestimation of left ventricular contractility due to rise in ejection fraction caused by changes in loading conditions (higher preload, lower afterload) [21] Secondly, activation of neuroendocrine compensatory mechanisms may increase afterload, which in turn may subsequently decrease ejection fraction [22] Thirdly, left ventricular preload is dependant upon interventricular interaction which is exaggerated in cases of pulmonary hypertension [23] a frequent finding in DCM patients. Furthermore, dobutamine has variable influence on afterload, since it has been shown that it may decrease afterload by $10 \%$ in patients with mild heart failure, but may also increases afterload by $5 \%$ in patients with severe heart failure [24].

Despite all these potential drawbacks, the change in ejection fraction during stress has been shown to have crucial prognostic significance in patients with DCM. It is generally accepted that increase in ejection fraction by $\geq 5 \%$ or change from baseline ejection fraction by $\geq 20 \%$ during stress-echocardiography identifies patients with preserved left ventricular contractile reserve and better prognosis. Ejection fraction should be assessed by Simpson biplane formula. 


\section{Wall motion score index}

Wall motion score index has been traditionally used in stress-echocardiography for the detection of coronary artery disease [25]. Only two reports used this index of left ventricular contractility to assess prognosis and functional recovery of DCM patients [10,15]. Wall motion score index was assessed in a standard manner, by using 16 segment model of the left ventricle according to the recommendations given by American Society of Echocardiography [26]. The major potential drawback for use of this index is semiquantitive assessment of wall motion, which is even more subjected to inter- and intraobserver variability in DCM patients due to preexisting wall motion abnormalities and substantial number of patients with left bundle branch. It has been suggested that dobutamine induced change in wall motion score index of $\geq 0.44$ identifies patients who will do better during the follow-up.

\section{Cardiac power output}

This index is not sensitive to changes in afterload, and after optimization for preload accurately reflects contractile properties of the myocardium [27]. Noninvasive calculation of cardiac power output is relatively complex and requires special instrumentation [11]. The most practical formula to calculate cardiac power output in Watts was suggested by Cook and coworkers [28]:

Cardiac power output $=($ cardiac output $\times$ mean arterial pressure) $\times 2.22 \times 10^{-3}$

where cardiac output is calculated by multiplying aortic velocity-time integral by aortic valve area, and mean arterial pressure is calculated in a standard manner.

The major problem with this index is that its calculation is time consuming, requires skilled echocardiographer, and is subjected to numerous sources of error. Furthermore, very few cardiologist are familiar with this index which precludes its wider use. Suggested cut-off point between patients with respect to prognosis is dobutamine induced change in cardiac power output of $\geq 1 \mathrm{~W}$.

\section{Prognostic significance}

There is no doubt that change in left ventricular contractility during stress has considerable prognostic significance and may have profound effect on therapeutic strategy. We will review available data according to the means how contractile response was elicited.

\section{Low-dose dobutamine}

Most authors prefer low-dose dobutamine stress-echocardiography, probably because it is considered safe and is not time consuming. A report by Paelinck and coworkers has suggested that low-dose dobutamine can identify patients with atrial fibrillation induced dilated cardiomyopathy who will improve following restoration of sinus rhythm [29]. These authors concluded that low-dose dobutamine may be used to identify patients with tachycardiomyopathy.

It has been shown, in a small number of patients, that changes in left ventricular wall motion score index and ejection fraction during low-dose dobutamine echocardiography are predictive of improvement of left ventricular systolic performance during medium term follow-up (Figure 1) [15]. Since the degree of beta-receptor downregulation and desenzititation is a marker of progressive deterioration of left ventricular systolic function [30], the authors hypothetized that improvement in contractility during dobutamine infusion is greater in patients with preserved beta-receptor function who will subsequently show improvement in systolic performance.

These findings are further extended, so it has been shown that the presence of myocardial contractile reserve identifies patients who will respond favorably to beta-blocker therapy [31]. Furthermore, Drozd and coworkers have demonstrated that the incidence of cardiac death or need for cardiac transplantation is lower in patients with preserved contractile reserve. In this paper, multivariate analysis identified left ventricular end-systolic volume of less than $150 \mathrm{ml}$ after dobutamine infusion and no decrease of left ventricular end-diastolic volume after dobutamine infusion as significant predictors of combined end-point [32].

Contractile reserve has been shown to correlate well with peak oxygen consumption (Figure 2) [16]. At multivariate analysis in this report, only percentage change in endsystolic volume index was significantly associated with occurrence of cardiac death or hospitalization for worsening heart failure. The area under receiver-operating characteristic curve was similar for percentage change in endsystolic volume index and peak oxygen consumption $(0.86 \pm 0.04$ vs. $0.80 \pm 0.06)$. Additionally, a report by Paraskevidis and coworkers suggested that low-dose dobutamine may further refine prognosis in patients with maximal oxygen consumption between 10 and $14 \mathrm{ml} / \mathrm{kg} /$ min [13]. This finding may be used for prioritization of patients for cardiac transplantation.

\section{High-dose dobutamine}

Use of high-dose dobutamine is not associated with serious complications in DCM patients, and has an overall feasibility of $88.7 \%$. The most common adverse event requiring discontinuation of dobutamine infusion is occurrence of complex ventricular arrhythmias, which was noted in $8 \%$ of patients (frequent multifocal ventricular extrasystoles in $6.4 \%$ and nonsustained ventricular 
Group A

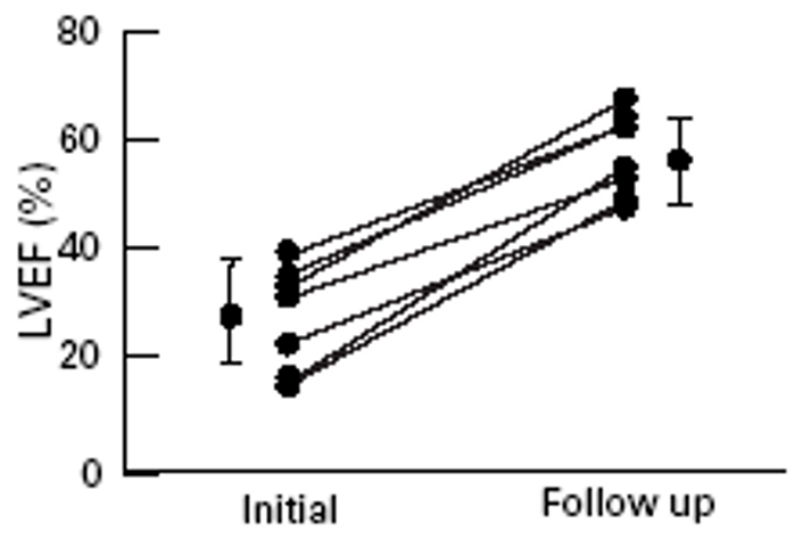

Group B

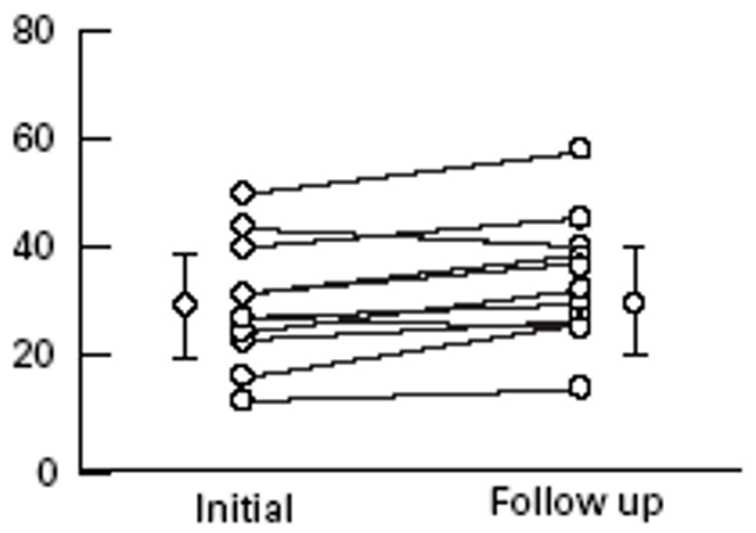

Figure I

Change in ejection fraction during follow-up in patients wih preserved (group A) and diminished (group B) contractile reserve. Abreviations: LVEF, left ventricular ejction fraction. From: Kitaoka $H$, Takata T, Yabe N, Hitomi N, Furuno T, Doi YL: Low dose dobutamine stress echocardiography predicts the improvement of left ventricular systolic function in dilated cardiomyopathy. Heart 1999;81:523-27.

tachycardia in $1.6 \%$ ) [10]. Although there are no data on the association of complex ventricular arrhythmias and serum potassium concentrations, it may be postulated that complex arrhythmias are more frequent in potassium depleted patients. Therefore, it appears prudent to check serum potassium level prior to high-dose dobutamine stress-echocardiography. Hypotension, defined as decrease in systolic blood pressure by more than 30 $\mathrm{mmHg}$, is very rare in the absence of complex ventricular arrhythmias and, in authors experience, occurs in less than $1 \%$ of patients with angiographically documented idiopathic DCM. Potential advantage of high-dose, as compared to low-dose, dobutamine echocardiography is that it may evoke more complete contractile response.
Very intriguing finding is that early in the course of DCM, dobutamine induced change in left ventricular contractile response and geometry is able to predict late spontaneous recovery of left ventricular systolic performance [14]. It is interesting that this study confirmed previous findings that increased left ventricular mass is associated with better outcome in DCM [33], and suggested that the presence of left ventricular hypertrophy implies the presence of myocardial contractile reserve.

The largest study that studied prognostic significance of high-dose dobutamine included 186 DCM patients. The major findings of this study are that dobutamine induced change in wall motion score index is able to identify 


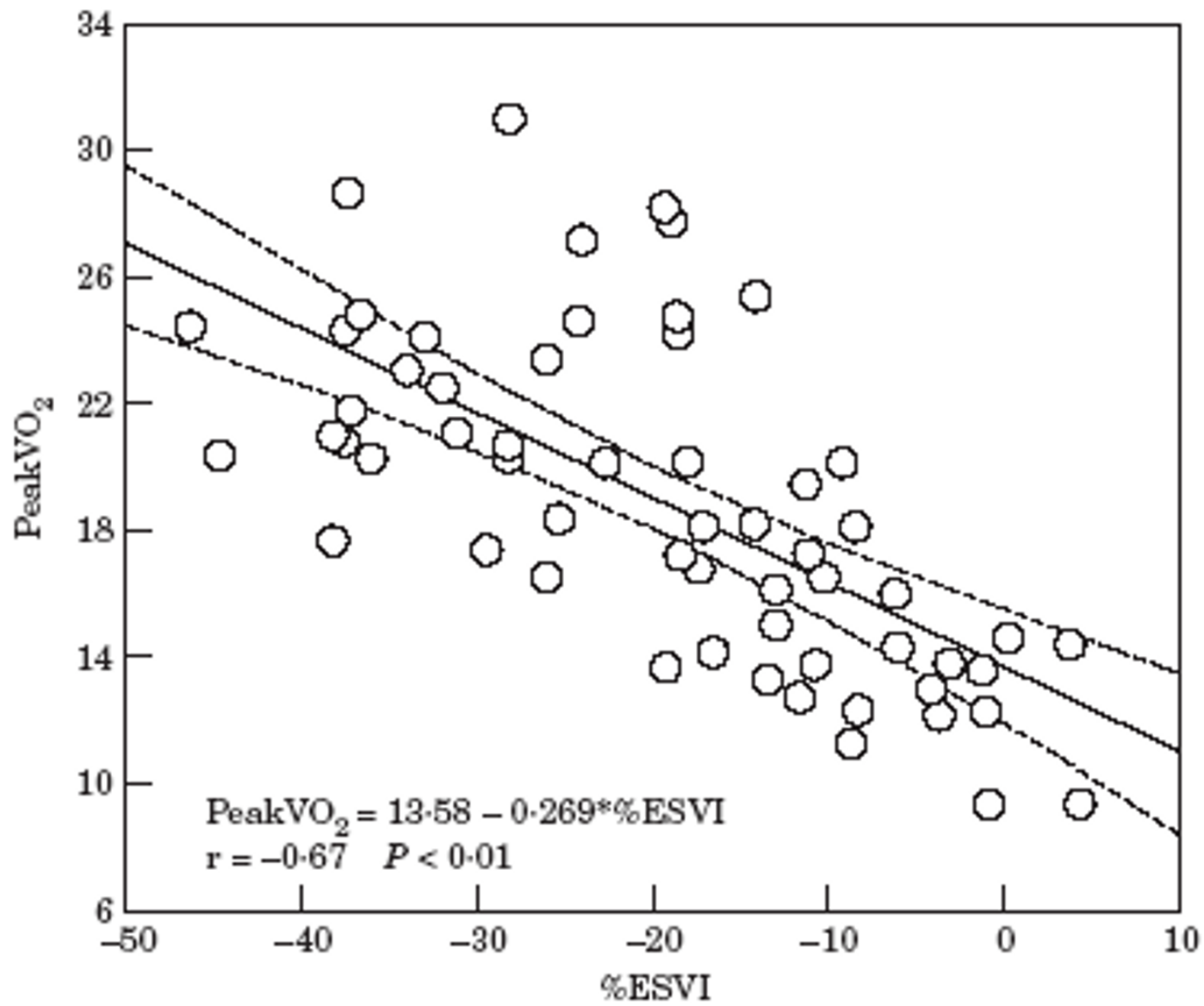

Figure 2

Linear correlation with $95 \%$ confidence interval between peak oxygen consumption and percent change in end-systolic volume index. Abreviations: \% ESVI, percent change in end-systolic volume index; peak VO2, peak oxygen consumption. From: Scrutinio D, Napoli $V$, Passantino A, Ricci A, Lagioia R, Rizzon P: Low-dose dobutamine responsivness in idiopathic dilated cardiomiopathy: relation to exercise capacity and clinical outcome. Eur Heart J 2000;2 I:927-34.

patients at greater risk for cardiac death during the followup (Figure 3), and that change in wall motion score index carries superior prognostic information than change in ejection fraction [10] Additionally, it has been reported that dobutamine induced change in ejection fraction by $\geq$ $8 \%$, assessed by radionuclide ventriculography, is prognostically superior to maximal oxygen consumption in patients with severe DCM [34].

Recent data by our group demonstrate that contractile reserve indices assessed by high-dose dobutamine correlate with myocardial histomorphometric features, suggesting that contractile reserve is strongly related to the degree of hystological disruption in DCM patients. Myo- cyte diameter and interstitial fibrosis showed strongest correlation with change in wall motion score index $(\mathrm{r}=$ 0.667, $\mathrm{p}<0.001$, and $\mathrm{r}=-0.567, \mathrm{p}=0.004$, respectively), followed by change in ejection fraction $(\mathrm{r}=-0.603, \mathrm{p}=$ 0.002 , and $\mathrm{r}=-0.467, \mathrm{p}=0.021$, respectively) [35].

\section{Dipyridamole}

It appears that dipyridamole may be used instead of dobutamine to evoke contractile response, since it is less arrythmogenic [36] better tolerated and yields similar prognostic information in patients with coronary artery disease [37]. Ability of dipyridamole to recruit contractile reserve is mediated through increase in coronary blood flow and accumulation of endogenous adenosine [38,39]. 


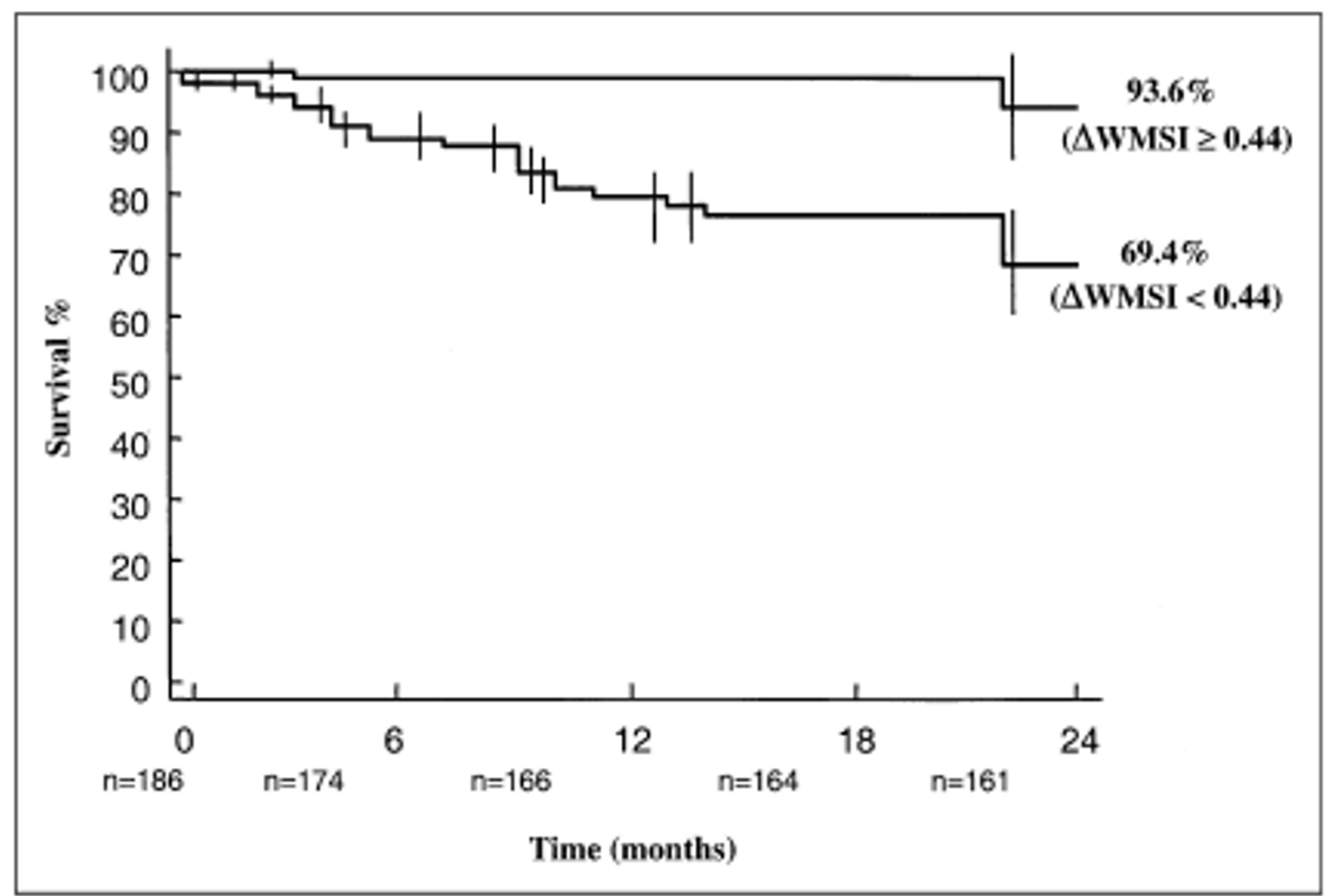

Figure 3

Kaplan-Meir survival curves (only cardiac deaths were considered) in patients stratified according to the dobutamine induced change in wall motion score index. Abbreviations: $\triangle W M S i$, change in wall motion score index. From: Pratali L, Picano E, Otašević P, Vigna C, Palinkas A, Cortigiani L, Dodi C, Bojić D, Varga A, Csanady M, Landi : Prognostic significance of the dobutamine echocardiography test in idiopathic dilated cardiomyopathy. Am J Cardiol. 200;88: $1374-8$.

Potential advantage of dipyridamole over dobutamine stress-echocardiography is that the former is not affected by the use beta-blocking agents which are frequently used in DCM patients. Only one study recently examined ability of dipyridamole to predict prognosis in DCM patients. The authors concluded that increase in wall motion score index $\geq 0.15$ during dipyridamole stress identifies patients who are more likely to survive during the mean follow-up of more than three years [19]. Reported overall feasibility of dipyridamole stress-echocardiography in this study was $99.2 \%$, which is significantly higher than previously reported feasibility of dobutamine stress-echocardiography.

\section{Exercise}

As previously said, there are no echocardiographic studies on exercise induced contractile response in DCM patients. However, Nagaoka and colleagues used radionuclide ventriculography to measure increase in ejection fraction during exercise in DCM patients with mild symptoms, and concluded that change in ejection fraction $<4 \%$ identifies patients with worse prognosis [17]. Additionally, it has been suggested that variables, such as cardiac power output, obtained by direct hemodynamic measurements during exercise may have important prognostic implications in patients with systolic dysfunction [12]. 


\section{What about the right ventricle?}

Right ventricular contribution to global cardiac performance is minor in subjects with normal or mildly depressed left ventricular systolic function, but may become more important in patients with advanced left heart failure [40]. Previous studies have suggested that right ventricular enlargement is a strong marker for adverse prognosis in DCM patients [41], as well as that right ventricular long axis excursion is predictive of exercise tolerance [42].

However, there are only limited reports of the prognostic value of right ventricular contractile reserve in patients with DCM. DiSalvo and colleagues have demonstrated that an increase in RVEF to $>35 \%$ during exercise is the only independent predictor of event-free survival in patients with advanced heart failure [43]. It has been also shown that preserved right ventricular contractile reserve (measured by pressure-area relations) induced by lowdose dobutamine infusion was associated with a good 30day outcome in patients with NYHA class IV heart failure [44].

Data from our laboratory support prognostic significance of high-dose dobutamine induced change in right ventricular fractional area change [45]. It appears that fractional area change of $>9 \%$ identifies patients with more favorable outcome. More importantly, these data suggest that patients in whom contractile reserve of both ventricles is preserved will most likely have good prognosis.

\section{What role for stress-echocardiography?}

Despite the wealth evidence that favor use of stressechocardiography in patients with DCM, there is no clearcut algorithm about its use in risk stratification and therapeutic strategy. The reasons for this are not clear, but probably reflect the lack of standardized protocol and measurements of left ventricular contractile reserve.

We strongly believe that stress-echocardiography should be used as a standard procedure, at least in centers which do not have access to cardiopulmonary testing, since data obtained when patients are subjected to some form of stress have far greater prognostic significance than data obtained at rest. Furthermore, stress-echocardiography should be used in patients who are not able to exercise or fail to achieve expected work load. Stress-echocardiography may also play an important role for detailed risk stratification in patients with maximal oxygen consumption of $10-14 \mathrm{ml} / \mathrm{kg} / \mathrm{min}$. The choice of stress-protocol, at least for the time being, should be based upon local expertise and preferences of attending physician.

\section{Future directions}

There is an obvious lack of studies that will contribute to standardization of stress-echocardiographic protocol.
Head-to-head comparison of stressors, including low- and high-dose dobutamine, dipyridamole, and exercise, has to be performed in order to rank their ability to predict prognosis. Similar comparisons have to be made for various indices of left ventricular contractility. Additionally, it is not clear should the patients be tested with or without beta-blocker therapy, and how this therapy may affect our choice of stressor. Last but not the least, novel echocardiographic techniques that can easily assess regional and global contractility, like tissue Doppler imaging and strain-rate imaging, have not yet been tested in a prospective manner.

In conclusion, stress-echocardiography can be a valuable tool for the assessment of patients with DCM, but a lot of work has to be done before it becomes a part of a routine work-up.

\section{References}

I. Gillum RF: Idiopathic cardiomyopathy in the United States, | 970- | 982. Am Heart ] | 986, I | |:752-5.

2. Braunwald E: Shattuck lecture - Cardiovascular medicine at the turn of the millennium: triumphs, concerns, and opportunities. N Engl J Med 1997, 337:1360-9.

3. Parameshwar J, Keegan J, Sparrow J, Sutton GC, Poole-Wilson PA: Predictors of prognosis in severe chronic heart failure. Am Heart J 1992, I 23:42|-6.

4. Mancini D, Eisen $H$, Kussmaul W: Value of peak oxygen consumption for optimal timing of cardiac transplantation in ambulatory patients with heart failure. Circulation 1991, 83:778-86.

5. Levine $A B$, Levine TB: Patient evaluation for cardiac transplantation. Prog Cardiovasc Dis 1991, 33:219-28.

6. Coats AJS, Adamopoulos S, Radaelli A, McCance A, Meyer TE, Bernardi L, Solda PL, Davey P, Ormerod O, Forfar C: Controlled trial of physical training in chronic heart failure. Circulation 1992 , 85:21|9-31.

7. Wilson JR, Mancini DM, Dunkman B: Exertional fatigue due to skeletal muscle dysfunction in patients with heart failure. Circulation 1993, 87:470-5.

8. Fleg JL, Lakatta EG: Role of muscle loss in the age-associated reduction in $\mathrm{VO}_{2}$ max. J Appl Physiol 1988, 65: I |47-51.

9. Wilson JR, Rayos G, Yeoh T, Gothard P: Dissociation between peak exercise consumption and hemodynamic dysfunction in potential heart transplant candidates. J Am Coll Cardiol 1995, 26:429-35

10. Pratali L, Picano E, Otašević P, Vigna C, Palinkas A, Cortigiani L, Dodi C, Bojić D, Varga A, Csanady M, Landi P: Prognostic significance of the dobutamine echocardiography test in idiopathic dilated cardiomyopathy. Am J Cardiol 200।, 88( I 2):|374-8. 200 | Dec 15

II. Mannor A, Shneeweiss A: Prognostic value of noninvasively obtained left ventricular contractile reserve in patients with severe heart failure. J Am Coll Cardiol 1997, 29:422-28.

12. Griffin BP, Shah PK, Ferguson J, Rubin SA: Incremental prognostic value of exercise hemodynamic variables in chronic congestive heart failure secondary to coronary artery disease or to dilated cardiomyopathy. Am J Cardiol I991, 67:848-53.

13. Paraskevidis IA, Adamopoulos S, Kremastinos Th: Dobutamine echocardiographic study in patients with nonischemic dilated catdiomyopathy and prognosticall borderline values of peak exercise oxygen consumption: I8-month follow-up study. J Am Coll Cardiol 200I, 37: I685-9I.

14. Naqvi TS, Goel RK, Forrester JS, Siegel RJ: Myocardial contractile reserve on dobutamine echocardiography predicts late spontaneous improvement in cardiac function in patients with recent onset idiopathic dilated cardiomyopathy. I Am Coll Cardiol 1999, 34: 1537-44. 
15. Kitaoka H, Takata T, Yabe N, Hitomi N, Furuno T, Doi YL: Low dose dobutamine stress echocardiography predicts the improvement of left ventricular systolic function in dilated cardiomyopathy. Heart 1999, 81:523-27.

16. Scrutinio D, Napoli V, Passantino A, Ricci A, Lagioia R, Rizzon P: Lowdose dobutamine responsivness in idiopathic dilated cardiomiopathy: relation to exercise capacity and clinical outcome. Eur Heart J 2000, $21: 927-34$.

17. Nagaoka H, Isobe N, Kubota S, lizuka, Imai S, Suzuki T, Nagai R: Myocardial contractile reserve as prognostic determinant in patients with idiopathic dilated cardiomyopathy without overt heart failure. Chest 1997, I I I:344-50.

18. Griffin BP, Shah PK, Ferguson J, Rubin SA: Incremental prognostic value of exercise hemodynamic variables in chronic congestive heart failure secondary to coronary artery disease or to dilated cardiomyopathy. Am J Cardiol 1991, 67:848-53.

19. Pratali L: Prognostic value of contractile reserve during dipyridamole stress-echocardiography in idiopathic dilated cardiomyoptahy. Eur J Heart Fail 2005 in press.

20. Rankin LS, Moos S, Grossman W: Alterations in preload and ejection phase indices of left ventricular performance. Circulation 1975, $51: 910-9$

21. Grossman W: Evaluation of systolic and diastolic function of the myocardium. In Cardiac catheterization, angiography and intervention Edited by: Baim DS, Grossman W. Williams and Wilkins, Baltimore; 1996:333-58.

22. Viquerat CE, Daly P, Swedberg K: Endogenous cateholamine levels in chronic heart failure: relation to the severity of hemodynamic abnormalities. Am J Med I985, 78:455-60.

23. Carrol JD, Lang RM, Neumann A, Borow KM, Rajfer SI: The differential effects of positive inotropic and vasodilator therapy in patients with congestive cardiomyopathy. Circulation 1986 74:815-22

24. Borow KM, Lang RM, Neumann A, Carrol JD, Rajfer SI: Physiologic mechanisms governing hemodynamic responses to positive inotropic therapy in patients with dilated cardiomyopathy. Circulation 1988, 77:625-37.

25. Beleslin BD, Ostojić M, Stepanović J, Djordjevic-Dikic A, Stojkovic S, Nedeljkovic M, Stankovic G, Petrasinovic Z, Gojkovic L, VasiljevicPokrajcic Z: Stress echocardiography in the detection of myocardial ischemia: head-to-head comparison of exercise, dobutamine, and dipyridamole tests. Circulation 1994, 90: I I68-76.

26. Schiller NB, Shah PM, Crawford M, DeMaria A, Devereaux R, Feingebaum H, Gutgesell H, Reichek N, Sahn D, Schnittger I: Recommendations for quantitation of the left ventricle by twodimensional echocardiography. J Am Soc Echocardiography 1989, 2:358-67.

27. Kass DA, Beyar R: Evaluation of contractile state by maximal ventricular power divided by the square end-diastolic volume. Circulation 199|, 84:1698-708.

28. Cooke GA, Marshall P, Al-Timman JK: Physiological cardiac reserve: development of a non-invasive method and first estimates in man. Heart 1998, 79:289-94.

29. Paelinck B, Vermeersch P, Stockman D, Convens C, Vaerenbeg M Usefulness of low-dose dobutamine stress echocardiography in predicting recovery of poor left ventricular function in atrial fibrillation dilated cardiomyopathy. Am J Cardiol 1999 , 83: $1668-70$.

30. Fowler MB, Laser JA, Hopkins GL, Minobe W, Bristow MR: Assessment of beta-adrenergic receptor pathway in the intact failing human heart: progressive receptor down-regulation and subsensitivity to agonist response. Circulation 1986 74: 1290-1302.

31. Jourdain P, Funck F, Fulla Y, Hagege A, Bellorini M, Guillard N, Loiret J, Thebault $B$, Desnos M: Myocardial contractile reserve under low doses of dobutamine and improvement of keft ventricular ejection fraction with treatment by carvedilol. Eur J Heart Fail 2002, 4:269-76.

32. Drozd J, Krzeminska-Pakula M, Plewka M, Ciesielczyk M, Kasprzak JD: Prognostic value of low-dose dobutamine echocardiography in patients with dilated cardiomyopathy. Chest 2002, 121:1216-22.

33. Ida K, Sersu MF, Fujieda K: Pathologig significance of left ventricular hypertrophy in dilated cardiomyopathy. Clin Cardiol 1996, 19:704-8.
34. Ramahi TM, Longo MD, Cadariu AR, Rohlfs K, Slade M, Carolan S, Vallejo E, Wackers FJTh: Dobutamine-iduced augmentation of left ventricular ejection fraction predicts survival of heart failure patients with severe non-ischemic cardiomyopathy. Eur Heart J 200I, 22:849-56.

35. Otašević P, Popović ZB, Vasiljević JD, Vidaković R, Pratali L, Vlahović A, Nešković AN: Relation of myocardial histomorphometric features and left ventricular contractile reserve assessed by high-dose dobutamine stress echocardiography in patients with idiopathic dilated cardiomyopathy. Eur J Heart Fail 2005, 7:49-56.

36. Picano E, Marzullo P, Gigli G, Reisenhofer B, Parodi O, Distante A, L'Abbate A: Identification of viable myocardium by dipyridamole-induced improvement in regional left ventricular function assessed by echocardiography in myocardial infarction and comparison with thallium scintigraphy at rest. $\mathrm{Am} J$ Cardiol 1992, 70:703-10.

37. Pingitore A, Picano E, Varga A, Gigli G, Cortigiani L, Previtali M, Minardi G, Colosso MQ, Lowenstein J, Mathias W Jr, Landi P: Prognostic value of pharmacological stress echocardiography in patients with known or suspected coronary artery disease: a prospective, large-scale, multicenter, head-to-head comparison between dipyridamole and dobutamine test. Echo-Persantine International Cooperative (EPIC) and EchoDobutamine International Cooperative (EDIC) Study Groups. J Am Coll Cardiol 1999, 34: I769-77.

38. Biaggioni I, Olafsson B, Robertson RM, Hollister AS, Robertson D: Cardiovascular and respiratory effects of adenosine in conscious man. Evidence for chemoreceptor activation. Circ Res 1987, 61:779-86.

39. Lucarini AR, Picano E, Marini C, Favilla S, Salvetti A, Distante A: Activation of sympathetic tone during dipyridamole test. Chest 1992, 102:444-7.

40. Bernard D, Alpert JS: Right ventricular function in health and disease. Curr Probl Cardiol 1987, 13:423-49.

4I. Lewis JF, Webber JD, Sutton LL, Chesoni C, Currz CL: Discordance in degree of right and left ventricular dilatation in patients with dilated cardiomyopathy: recognition and clinical implications. J Am Coll Cardiol 1993, 2 I:649-54.

42. Webb-Peploe KM, Henein MY, Coats AJ, Gibson DG: Echo derived variables predicting exercise tolerance in patients with dilated and poorly functioning left ventricle. Heart 1998, 80:565-69.

43. DiSalvo TG, Mathier M, Semigran MJ, Dec GW: Preserved right ventricular ejection fraction predicts exercise capacity and survival in advanced heart failure. J Am Coll Cardiol 1995, 25: $1143-53$

44. Gorcsan J, Murali S, Counihan PJ, Mandarino WA, Kormos RL: Right ventricular performance and contractile reserve in patients with severe heart failure: assessment by pressure-area relations and association with outcome. Circulation 1996, 94:3190-7.

45. Otasevic P, Popovic Z, Pratali L, Vlahovic A, Vasiljevic JD, Neskovic $A N$ : Right versus left ventricular contractile reserve in oneyear prognosis of patients with idiopathic dilated cardiomiopathy: assessment by dobutamine stress-echocardiography. Eur J Echocar 2005 in press.

Publish with Bio Med Central and every scientist can read your work free of charge

"BioMed Central will be the most significant development for disseminating the results of biomedical research in our lifetime. "

Sir Paul Nurse, Cancer Research UK

Your research papers will be:

- available free of charge to the entire biomedical community

- peer reviewed and published immediately upon acceptance

- cited in PubMed and archived on PubMed Central

- yours - you keep the copyright 